\title{
A Review Paper on Origin of Honeycomb Structure and its Sailing Properties
}

\author{
S. N. Abhinav ${ }^{1}$ and Madhava Varma Budharaju ${ }^{2}$ \\ ${ }^{1}$ M. Tech Student in MVGR College Vizianagaram, \\ ${ }^{2}$ Senior Assistant Professor and Faculty of Mechanical Engineering
}

\begin{abstract}
Aero-engine developers focus more on increasing the efficiency of the engine. When it comes to efficiency the most effective factors that are to be considered are Weight, fuel consumption, working temperature, etc. As the aero-engine works at a higher temperature, the materials that are used in it has to withstand the higher temperatures. The best solution for increasing efficiency is sealing. The labyrinth seal is used to reduce the pressure and also acts as a cooling interface to the engine parts. The abradable structures are integrated into labyrinth seals. Those surfaces are coated with composite fabrication or substrates that are coated with sacrificial materials. Those sacrificial Materials are Honeycomb materials. Honeycomb material has lightweight in a design criterion and has excellent fatigue resistance. In this review paper the honeycomb origin, manufacturing, and few mechanical properties are explained.
\end{abstract}

\section{INTRODUCTION}

Honeycomb comprises of a variety of open cells, framed from extremely slight sheets of material attached. The use of honeycomb in the aero-engine applications is increasing day by day because of its properties like lightweight, good fatigue resistance, and low in cost. The honeycomb material is made up of Hastelloy-X and Haynes 214 which are alloys of Inconel 718. There are nickel-based superalloys that are good at high temperatures. They are cheap at cost, so economically it is good to use. The use of honeycomb in the aero-engine will increase the life span of engine parts and will give good efficiency to the engine.[1] Honeycomb showcase is a quick and as yet developing business sector which offers different materials for any utilization. As it were Nomex honeycomb showcase is relied upon to collect $\$ 383.3$ million by 2021 and register a CAGR (compound yearly development pace) of 8.5\% somewhere in the range of 2016 and 2021[3].

Face sheets can be made of metals (aluminum, hardened steel), composites strengthened with carbon fibers, glass filaments or aramid strands, plastics, wood or container [2, 4]A core can be utilized: foam, honeycomb, or normal materials like balsa wood or plug. Foam materials can be made up of plastics which will be like PVC, PU, PE, PS, PES, PET, PMI, PEI, and so forth.[4] It is additionally conceivable to utilize metals as foam however that isn't well known because foams have lower quality than honeycombs and lower work temperature (foams: $>180^{\circ} \mathrm{C}$, honeycombs: $>250^{\circ} \mathrm{C}$ ). They are utilized in components working on low loads however for the most part as an isolating panel.

Honeycomb materials establish the greatest gathering of core materials utilized in sandwich structures. They can be utilized in the type of metallic and non-metallic honeycomb. From metallic the frequent use is aluminum $(3003,5052,5056)$, which can be applied in structures working in temperature up to $180^{\circ} \mathrm{C}$. Infrequently metallic honeycomb is produced using steel (17-PH, $316 \mathrm{~L}, 347)$, titanium $(6 \mathrm{Al}-4 \mathrm{~V}, 6 \mathrm{Al}-2 \mathrm{Sn}-4 \mathrm{Zr}-2 \mathrm{Mo})$, lead, or copper. Most regularly they are produced using non-metallic materials. Those could be composite materials strengthened by aramid fiber (Kevlar, Nomex), carbon fiber, glass fiber and plastics (PVC, PET, PEI) [ 2,4,5, 6]

Honeycomb core materials are used in different application parts like driving edges, following edges, folds, spoilers, cowlings, fuselage, components inside the plane (floors, roofs, sideboards). Moreover, in the helicopter industry, they can be utilized as the fundamental and tail rotor cutting edges. Like in aeronautics, in the cosmonautic industry, mass is a significant boundary. Hence sandwich panels are so mainstream there. They are utilized in numerous vehicles as folds, outer boards of the body, driving edges, radar covers, in telescopes, drones, radio wires, space stations [4].

Sandwich materials are generally utilized in the marine industry, for Example in vessels, ships, yachts, speedboats building, or as components of moors in marinas. They are typically utilized in insides of boats as a body, hatches, applauds, stages, and so on $[4,7,8]$.

\section{HISTORY}

The Hexagonal state of regular honeycomb structural configuration employed by hive building creepy crawlies was observed in antiquity. In 1638, galileo discussed how a hollow solid material with lightweight can be strong when compared to the solid piece of material. The honeycomb structure was further supported in 1665 when Robert hook discovered that the cellular structure of cork has similar properties to the hexagons found in the honeycombs built by bees. This process became further indicated in 1859 when Darwin stated that the honeycomb was a highly efficient economization of effort and wax. In 1877, F.H Kustermann invented a molding process to make honeycombs out of a mixture of glue and paper. In 1890 Julius Spiegel Discovered a molding process for the repeating hexagonal shape for sheet metals. In 1901, Hans Heilbrun invented an expansion production-based paper honeycomb production process. The structural usage and honeycomb construction design process took off in 1914 when R.Hofler and S. Renyi received a patent for the use of honeycombs as a structural element. Where the idea took off was in 1915, with Hugo Junkers receiving a patent to use honeycomb cores on airplanes. In 1919 the first aircraft sandwich panel was fabricated using thin mahogany facings bonded to an end-grain balsa wood core. It was used 
as the primary structure of the pontoons of a seaplane. But due to the moisture problem, they started to use honeycomb aluminum sandwich structure cores in the aircraft. In 1938, Norman de Bruyne patented the adhesive necessary to bond honeycombs together in airplane randomness. Due to an increase in new methods and technologies, bonding methods are also rapidly increased. Brazing is one of the strongest bonding methods which is being used rapidly. $[9,10]$

\section{MANUFACTURING PROCESS}

Manufacturing the honeycomb can be done in different ways, depending on the application of the use. Honeycomb can be manufactured in five different ways.

1. Adhesive bonding: almost $95 \%$ of the honeycomb is made by adhesive bonding. The highest temperature adhesive-bonded nodes can withstand is about $750{ }^{\circ} \mathrm{F}\left(399^{\circ} \mathrm{C}\right)$

2. Brazing: Brazing is an application of the joining process, which joins the material above the temperature of $800^{\circ} \mathrm{F}$ $\left(427^{\circ} \mathrm{C}\right)$. Generally used for high-temperature applications.

3. Thermal Fusion: The highest temperature for the nodes to withstand is about $400^{\circ} \mathrm{F}\left(204^{\circ} \mathrm{C}\right)$

4. Resistance Welding: it is also a high-temperature process for the materials that withstand the temperature of $1825^{\circ} \mathrm{F}\left(996^{\circ} \mathrm{C}\right)$

5. Diffusion Bonding: It is also a joining process where the surface heated in the furnace to a certain temperature of $1750^{\circ} \mathrm{F}$ $\left(800^{\circ} \mathrm{C}\right)$

Two basic techniques are used to convert the sheet material into honeycomb

(i) Expansion Process: In this process, both metallic cores and non-metallic cores can be formed. But there are slight changes in both the methods because plastic deformation of metals is permanent after certain elasticity but in non-metallic cores the plastic deformation is temporary. First, the foil sheets are applied by a corrosive resistance coating and then adhesive lines are printed on the sheets for the expansion process. Then the honeycomb surface is cut into required thickness slices and then expanded to a certain elasticity. Whereas in the non-metallic core after the expansion it is placed in the rack and then dipped in the resin which is hot set in the oven. The dipping cycle is repeated until the desired density is obtained. Generally, the dipping cycle will be 3 to 4 cycles.[5]

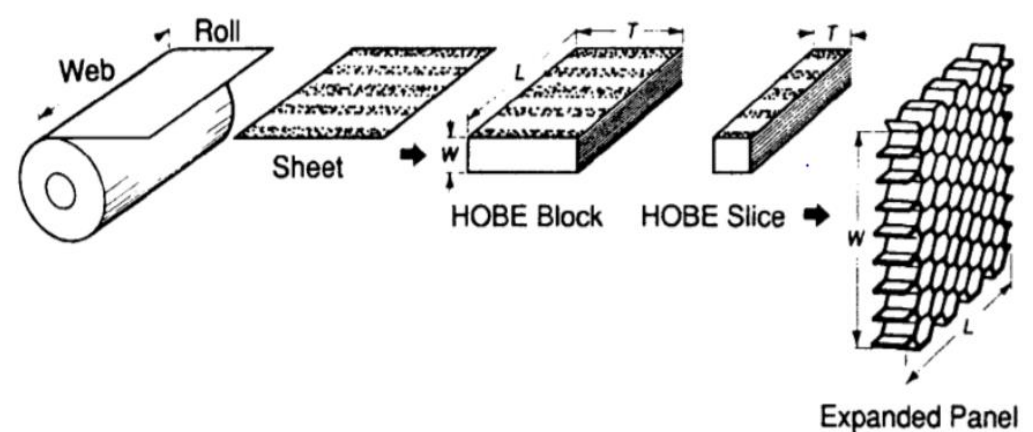

Figure 1 Expansion Manufactur

(ii) Corrugation Method: It is the original technique used to fabricate the honeycomb core for making higher density. First, the foil sheet is passed to the corrugated rolls where it becomes the corrugated sheets then the adhesive coating is applied to it. After that, it is stacked and cured in an oven. Only a little pressure is applied on the sheet so the total weight of the honeycomb core is $10 \%$ of the node adhesive. Where in the expansion process it is about $1 \%$ or less of the node adhesive because a lot of pressure is applied in it. Instead of using adhesives in the nodes for high-temperature materials, we can use techniques like Brazing, diffusion bonding, or spot welding.[5] 


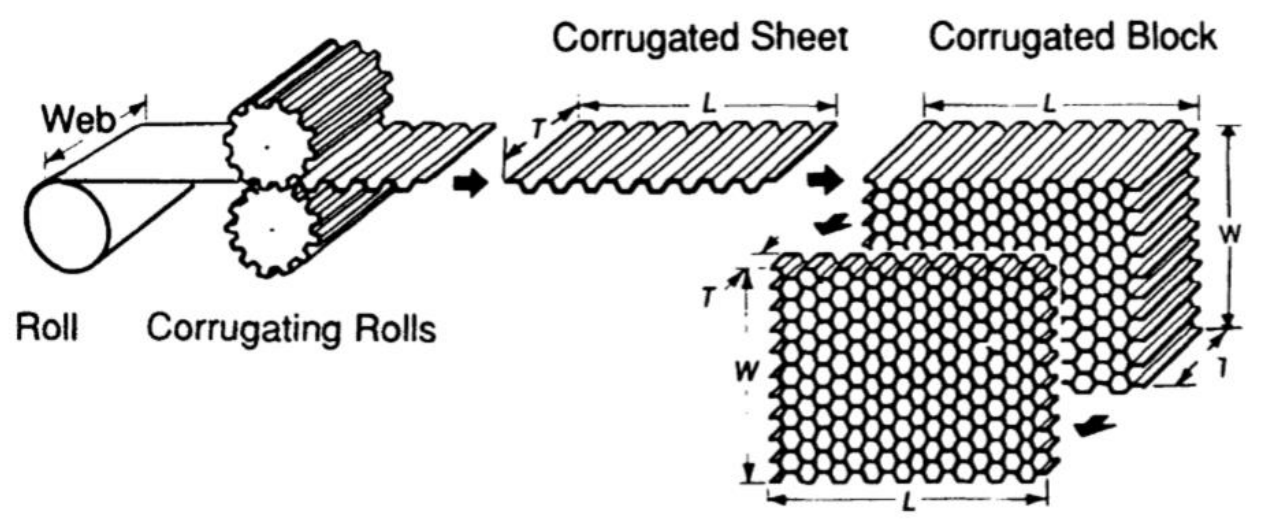

Figure 2 Corrugation Manufacturing Process

\section{PROPERTIES}

The wide utilization of these materials has made a lot of regular use on a daily bases. These days sandwich materials assume a significant job in numerous ventures and regular day to day existence. Of all the previously mentioned kinds of cores, honeycomb cores are the most normally and broadly utilized.

To be certain that composite material meets the desires, it must be altogether examined before it is guaranteed. Each material has its particular properties and based on them it is planned to utilize in a different application. Sandwich materials test strategies depend on two fundamental classes: mechanical tests and physicochemical tests. These days, a lot of tests that exist, how to evaluate the properties of composite materials. It very well may be American Section of the International Association for Testing Materials principles (ASTM), global principles (ISO), United States military guidelines (MIL-STD), aviation material norms (AMS) and own guidelines of the greatest creation organizations, for example, Boeing (BMS), McDonnell Douglas (MMS) and so forth [11-14]

\section{STRESS ANALYSIS}

The honeycomb structure has a uniform stress analysis when compared to other structural elements. To obtain the stress analysis we use the sandwich structure of a honeycomb. The sandwich structure has thin and dense facing material bonded to a thick core. As the facing elements are relevantly weak, but when it comes to working conditions they perform a good stiff and strong bond. In the sandwich structure, the facing sheets will take the load in compression and tension whereas the core takes the shear load. So the honeycomb does not show any bending as it is resistant to it. The bending modulus of honeycomb is Zero. Different sandwich materials are shown in figure3.

In the figure, the woodblock has zero bending momentum at the center and the shear forces are taken at the outer surfaces. When it comes to a wide flange beam or I-beam the flanges take the bending momentum and the web takes the shear loads. But this needs a lot of weight factors. But the honeycomb which we use in the aircraft needs less weight in the flanges. So to reduce the weight factor in the aircraft the thickness of the flange is reduced. When the flange thickness is reduced the pressure will act on the center of the plane and it leads fo buckling factor. So the honeycomb is used as a material in the flanges as it supports the buckling factor and takes the load of yield stress. The honeycomb has the thin facing sheet which will take the buckling factor.[15].

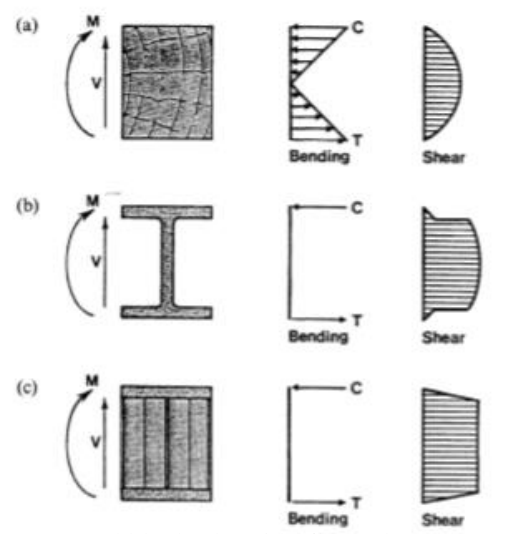

Figure 3 (a) Wood block; (b) wide-flange beam; (c) sandwich construction.

Zhang and Ashby [17] then developed an analytical model based on the buckling formulas of the plates, which allowed shear to collapse stress to be calculated but did not investigate the nonlinear domain itself. They also stated the experimental 
difficulties to the fact that it is impossible to test honeycomb alone in pure shear. Pan et al. [18,19] analyzed the shear buckling of aluminum honeycombs and proposed improved analytical methods for calculating the buckling load. Bianchi et al. [20] analyzed the nonlinear responses of honeycomb made of aluminum in shear experiments and proposed finite element modeling with initial imperfections. The analysis also focused on their behavior in the orthotropic or off-axis directions. The model that was made which makes it possible to correctly guess the stiffnesses and the critical buckling load, which is considered here, as in previous publications, as the sizing load. Gornet et al. [21] analyzed nonlinear shear behavior using the asymmetrical shear test but proposed a nonlinear model based on damage mechanics only in compression. The stress portions are shown in the figure below

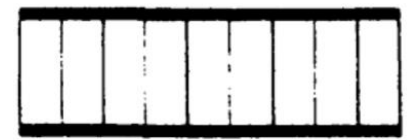

HONEYCOMB PANEL

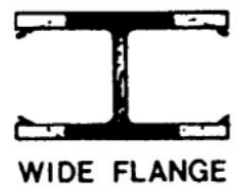

WIDE FLANGE

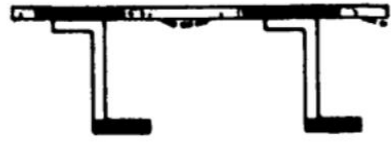

SHEET AND STRINGER

Figure 4 Fully stressed portions

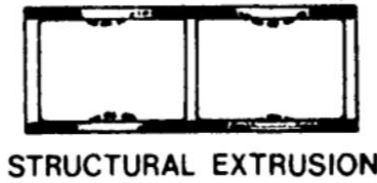

STRUCTURAL EXTRUSION

FATIGUE STRESS ANALYSIS

The material strength cannot be decided through a single static load. Material strength will be known when it is subjected to repeated variations in the load. The Phenomenon of decreasing the strength of the material is known as fatigue. A fatigue failure begins with a small crack. When the material is subjected to a load then the stress acts more on the crack and the stressed area decreases in size and the stress increases in magnitude until the remaining area fails suddenly. So the failure occurs either progressively or sudden fracture. Honeycomb is extensively used due to its high strength to weight ratio. Generally, fatigue stress occurs due to the stress riser like abrupt changes in holes, notches, etc. But honeycomb has a wellbonded node attachment which will make the stress to act uniformly on it. The face sheet will take all the compression and tension which will act on it. The fatigue failure mostly occurs on the node attachment points. The stress will shear buckling and diagonal tension cracking the cell wall.

Investigations of the bending-fatigue behavior of sandwich beams were performed by Olsson and Lönnö [22], Echtermeyer et al. [23], Allen, and Shenoi [24], Lagunegrand et al. [25], Burman and Zenkert [26]. It was found that under fatigue cycling of constant amplitude, the nucleation phase of fatigue damage extends over the major part of the fatigue life, while the phase of defect propagation is very short. The fatigue life of a component will also be adversely affected by damage, though the magnitude of this reduction in fatigue life is often more difficult to establish [27,28]. The fatigue of damaged (initial defects structures may be determined by the extensive testing of specimens with various defects at different load levels [29].

The honeycomb factors that influence the fatigue limit reach of the core are recorded underneath along with some broad remarks.

- Poor cell design causes low fatigue quality.

- Slightly higher fatigue qualities are found for little cell sizes.

- The fatigue qualities are somewhat lower for the core with a thickness greater than $1 \mathrm{in}$.

- Slightly lower fatigue qualities happen with lower thickness core.

- The $\mathrm{L}$ direction holds a greater amount of its fatigue quality than does the $\mathrm{W}$ direction.

The varying load cycle test is done on all types of honeycomb structures. Generally, they are indicated through the strength failure (S-N) curve. It is found that all the material have the endurance limit more than $40 \%$ the graph is listed below

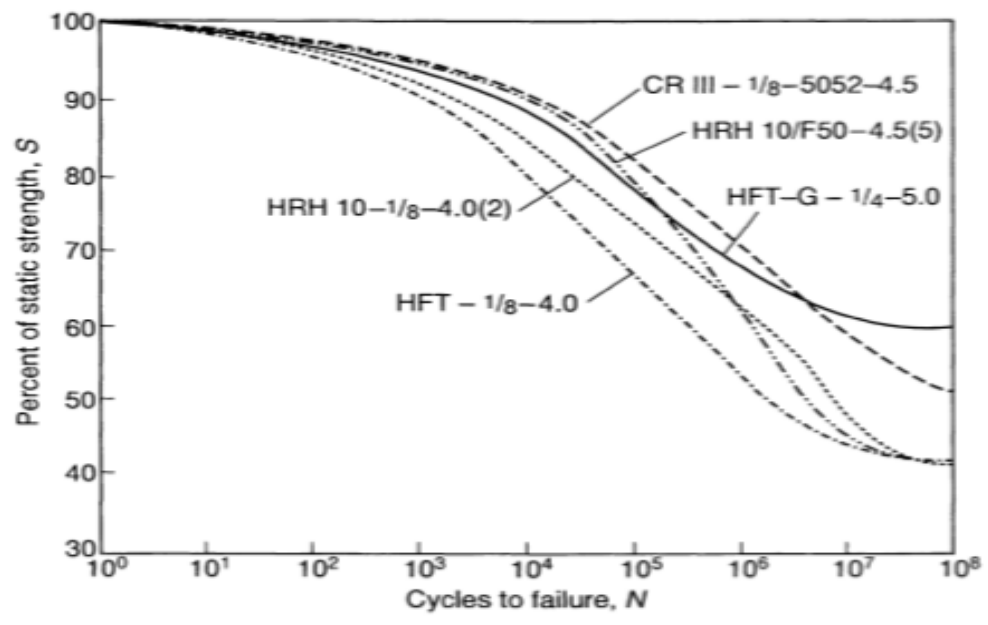

Figure $5 \mathrm{~S}-\mathrm{N}$ curves at room temperature for $112 \mathrm{in.}(12.7 \mathrm{~mm})$ thick honeycomb. 


\section{CREEP}

Creep is an increase in strain with time, gradual flow, or deformation of a material under stress. Creep failure is of three stages. The first stage, or primary creep, starts at a rapid rate and slows with time. The second stage or secondary creep will fail slowly in a uniform way, while the third stage or tertiary creep exhibits an accelerating rate and terminates by failure of the material. The creep will not be a failure if the material is at room temperature but at elevated temperature, it needs to be considered. The adhesive bonding that is used in the honeycomb to attach the nodes should be strong enough. The major stress raisers will effect more on the node points. If the temperature of the material exceeds an elevated temperature then the life span of the material gradually gets decreased. So the adhesive curing should always be cured at the high elevated temperatures. So that the material can withstand at the elevated temperatures and no creep failure occurs.

J. Pritchard, M.P. Ansell and R.J.H. Thompson dealing with the creep rate of wood and wood composites have focused on the influence of moisture content, temperature, stress level, species, and adhesive type[30, 31, 32]. V.P. Gressel and J.M. Dinwoodie investigated and said that the creep rate increases with increasing temperature, moisture content, and stress level. Resin types also affect creep rate due to their differing degrees of hydrophobicity [33, 34] Some of the conclusions that can be deduced from some of the testings that have been done are:

- the creep rate increases with increased core or facing stresses;

- the creep rate increases with increasing cell size;

- creep in the $\mathrm{L}$ direction of the honeycomb is less than that in the $\mathrm{W}$ direction;

- the creep rate decreases with increasing cure temperature and increasing cure time of the core-to-facing adhesive[16]

\section{CONCLUSION}

Honeycomb materials are widely used in the applications of aerospace and aircraft engines. The manufacturing honeycomb should be done very carefully to reduce the failures. It is always best to use an adhesive that is temperature cured as room temperature adhesives will normally creep more than elevated cured adhesives. Stress raisers will not become a factor if the node attachment is bonded properly. The honeycomb face sheets will take the bending momentum( one skin will take compression and the other will take tension) and the core will bare the shear loads. The weight of the honeycomb will be mostly of the weight of the core material. The weight of the honeycomb will be mostly of the weight of the core material. We use very thin face sheets as their weight will $1 \%$ or less of the honeycomb core. Most of the material that is used in air crafts is the honeycomb.

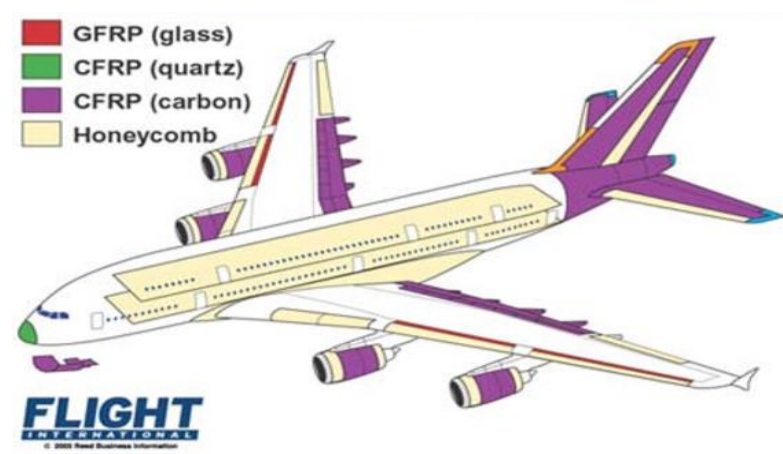

Figure 6 Materials used in aircraft

\section{REFERENCES}

[1] 431616 Unclassified AD Defence document center for scientific \& technical information

[2] DIAB Core Guide Rev 1, December 2012.

[3] Nomex Honeycomb Market by Application (Aerospace \& Defense, Transportation, Sporting Goods, and Others), Aerospace \& Defense, Sub Application (Interior and Exterior), and by Region - Global Forecasts to 2021, 09.10.2018, from http://www.marketsandmarkets.com/MarketReports/nomex-honeycomb-market-197303057.html

[4] CMH-17-6, 2013, Composite Materials Handbook, Volume 6 - Structural Sandwich Composites.

[5] HexWeb Honeycomb Attributes and Properties, A comprehensive guide to standard Hexcel honeycomb materials, configurations, and mechanical properties, 1999.

[6] Plascore Honeycomb Core For Commercial, Defense, and Space Applications, 2015.

[7] Composites Symposium 2011, 10.07.2017, from http://www.euroaviasevilla.es/compositesymposium/why_composites.php

[8] Wiśniowski W., 2014, „Twenty Years of Light Aircraft and Safety Program"(„XX lat program samolotów lekkich I bezpieczeństwa (PSLIB)", Transactions of the Institute of Aviation, No. 3(236), pp. 7-25 (in Polish).

[9] Cms Advanced Materials/news-events/news/the history of honeycomb consruction design.n68599.html/ https://www.scmgroups.com

[10] Bitzer.T (1997) Introduction. In : Honeycomb Technology. Springer Dordrecht. DOI https://doi.org/10.1007/978-94-011-5856-5_1

[11] International Organization for Standardization, 10.08.2017, from https://www.iso.org

[12] ASTM International, 01.09.2017, from https://www.astm.org

[13] SAE International, 01.09.2017, from http://standards.sae.org

[14] BMS Specification Revision Index, 01.09.2017, from http://active.boeing.com/doingbiz/d14426/ index.cfm

[15] Bitzer.T (1997) sandwich Design.In : Honeycomb Technology. Springer Dordrecht. DOI https://doi.org/10.1007/978-94-011-5856-5_3

[16] Bitzer.T (1997) Honeycomb Core.In : Honeycomb Technology. Springer Dordrecht. DOI https://doi.org/10.1007/978-94-011-5856-5_2

[17] Zhang J, Ashby MF. The out-of-plane properties of honeycombs. Int J Mech Sci 1992;34(6):475-89.

[18] Pan SD, Wu LZ, Sun YG, Zhou ZG, Qu JL. Longitudinal shear strength and failure process of honeycomb cores. Compos Struct 2006;72:42-6. 
[19] Pan SD, Wu LZ, Sun YG. Transverse shear modulus and strength of honeycomb cores. Compos Struct 2008;84:369-74.

[20] Bianchi G, Aglietti GS, Richardson G. Static and fatigue behavior of hexagonal honeycomb cores under in-plane shear loads. Appl Compos Mater 2012;19:97-115.

[21] Gornet L, Marguet S, Marckmann G. Modeling of Nomex honeycomb cores, linear and nonlinear behaviors. Mech Adv Mater Struct 2007;14:1-13

[22] Olsson KA, Lönnö A., Test procedures for foam core materials, In Olsson KA, Reichard RP, editors. Proceedings of the First International Conference on Sandwich Constructions. Solihull, UK: EMAS, UK, 1989, 293-318

[23] Echtermeyer AT, Buena L, McGeorge D, Sund OE. Four-point bend testing of GRP sandwich beams - Part 1. Der Norske veritas VR-91-P0013. 1991

[24] Allen HG, Shenoi RA. Flexural fatigue tests on sandwich structures, In: Weismann-Bermann D, Olsson KA, editors. Proceedings of the Second International Conference on Sandwich Constructions. Solihull, 1992, 499-517

[25] Lagunegrand L, Lorriot Th, Harry R, Wargnier H. Design of an improved four-point bending test on a sandwich beam for free edge delamination studies, Composites: Part B 37 (2006), 127

[26] Burman M, Zenkert D. Fatigue of undamaged and damaged honeycomb sandwich beams. J Sandwich Struct Mater (2000) 2, 50-74

[27] Kapil Mohana, Yip Tick Hon, Sridhar Idapalapati, Hong Pheow Seow Failure of sandwich beams consisting of alumina face sheet and aluminum foam core in bending Materials Science and Engineering A 409 (2005), 292-30

[28] A. Abbadi, Z. Azari, S. Belouatar, J. Gilbert, S. Dominick Static and fatigue characterization of honeycomb sandwich panels JNC14 Compiègne, French (2005)

[29] Demelio G, Genovese K, Pappalettere C, An experimental investigation of static and fatigue behavior of sandwich composite panels, Composites B Eng 32 (2001) 4, 299-308

[30] J. Pritchard, M.P. Ansell, R.J.H. Thompson, P.W. Bonfield, Wood Science, and Technology 35 (2001) $405-423$.

[31] A.P. Schniewind, R. Cal, Wood Science, and Technology 2 (1968) 188-206.

[32] T.L. Laufenberg, Creep testing of structural composite panels: a literature review and proposed standard, in Proceedings 21st International Particle/Composite Materials Symposium, Pullman, WA, USA, March 24-26, 1987, 1987.

[33] V.P. Gressel, Holz als Roh-und Werkstoff 30 (1972) 259-488.

[34] J.M. Dinwoodie, B.H. Paxton, C.B. Pierce, Wood Science, and Technology 15 (1981) 125-144 